\title{
Crop water use indicators to quantify the flexible phenology of quinoa (Chenopodium quinoa Willd.) in response to drought stress
}

\author{
Sam Geerts ${ }^{\mathrm{a}, *}$, Dirk Raes ${ }^{\mathrm{a}}$, Magali Garcia ${ }^{\mathrm{b}}$, Jorge Mendoza ${ }^{\mathrm{b}}$, Ruben Huanca ${ }^{\mathrm{b}}$ \\ ${ }^{a}$ K.U. Leuven University, Division of Soil and Water Management, Celestijnenlaan 200 E, B-3001 Leuven, Belgium \\ ${ }^{\mathrm{b}}$ Universidad Mayor de San Andres, UMSA, Facultad de Agronomía, La Paz, Bolivia
}

\section{A R T I C L E I N F O}

\section{Article history:}

Received 7 January 2008

Received in revised form 24 April 2008

Accepted 24 April 2008

\section{Keywords:}

Deficit irrigation

Water stress

Phenological development

Growing degree days

Modeling

Anthesis

Quinoa

\begin{abstract}
A B S T R A C T
Models can play an important role in agricultural planning and management. Thermal time accumulation is a common way of describing phenological development in crop models, but the sensitivity of this concept to water stress is rarely quantified. The effect of pre-anthesis droughts on the timing of anthesis and physiological maturity was assessed for quinoa (Chenopodium quinoa Willd.) var. 'Santa Maria', with the help of two field experiments (2005-2006 and 2006-2007) in the central Bolivian Altiplano. Various treatments with different sowing dates and irrigation applications were considered. To evaluate the effect of drought stress on crop development, drought stress during the first 60 days after sowing was assessed with three different stress indicators: the number of days that the soil water content of the root zone was above a threshold, the average relative transpiration, and the sum of daily actual transpiration, standardized for reference evapotranspiration $\left(\sum\left(T_{\mathrm{a}} / \mathrm{ET}_{0}\right)\right)$. The best indicator to quantify the effect of pre-anthesis drought stress on phenological development was $\sum\left(T_{\mathrm{a}} / \mathrm{ET}_{0}\right)$ cumulated until 60 days after sowing. This indicator showed a significant logarithmic relation with the time to anthesis and time to physiological maturity. Correlations of the drought stress indicator with thermal time accumulation were better than with calendar time accumulation. Due to an effect of post-anthesis droughts, the correlations of the drought stress indicator with the time to anthesis were stronger than with the time to physiological maturity. It was also demonstrated that deficit irrigation can contribute to a better agricultural planning due to a better control of the phenological development of quinoa. The proposed relations can be used for modeling phenological development of quinoa in drought prone regions and for efficient deficit irrigation planning.
\end{abstract}

(c) 2008 Elsevier B.V. All rights reserved.

\section{Introduction}

In current times of increasing water scarcity in agriculture (Howell, 2001), crop simulation models can play an important role (Hoogenboom, 2000). They allow studying possible scenarios that might occur in the future to adopt better management strategies (van Ittersum et al., 2003). The thermal time, growing degree day (GDD) or heat unit concept (Madariaga and Knott, 1951; McMaster and Wilhelm, 1997), is commonly the basis for modeling phenological development in crop models for different common crops (Stöckle et al., 2003; Brisson et al., 2003; Eitzinger et al., 2004; Yang et al., 2004) and under-utilized crops (Robertson et al., 2001; Soltani et al., 2006a,b; Adam et al., 2007; Al-Ahmadi and Kafi, 2007). The GDD concept describes crop development as a function

\footnotetext{
* Corresponding author. Tel.: +32 163297 54; fax: +32 16329760 .

E-mail addresses: sam.geerts@biw.kuleuven.be, samgeerts@yahoo.com (S. Geerts).
}

of temperature sums above a base temperature (lower limit) (Yang et al., 1995) and in some cases below a cut off temperature (upper limit) (McMaster and Smika, 1988). A correction of the concept for photoperiod sensitivity is often beneficial for the modeling quality (McMaster and Smika, 1988; Bertero et al., 1999b; Soltani et al., 2006a).

Azam-Ali and Squire (2002) mention that the concept of thermal time is valid over a wide range of environmental conditions, and is mostly unaffected by changes in solar radiation but that it is often sensitive to drought stress. As an example, McMaster and Wilhelm (2003) reported for wheat and barley a decreasing effect of drought stress on the length of the cropping cycle. McMaster and Smika (1988) already suggested that to improve the performance of GDD models (with or without the incorporation of photoperiodism), differences specific to a cultivar or due to drought stress should be included. Nevertheless, only a few crop growth models include a correction for drought stress, often in a generic way. Stöckle et al. (2003) include drought stress as a possible thermal time acceleration. Brisson et al. (2003) mainly 
include it as a factor accelerating maturity and senescence. Robertson et al. (2001) report a lack of published information on functional relationships between water and nutrient deficits and phenological development for different crops.

In this paper, the effect of drought stress on the phenological development of quinoa, cultivated in the Bolivian Altiplano, is quantified. Quinoa (Chenopodium quinoa Willd.) is an Andean seed crop that is rapidly gaining interest throughout the world (Jacobsen, 2003; Bhargava et al., 2006). The crop has a very high nutritional value (Comai et al., 2007) and is well adapted to the unfavorable soil and climatic conditions prevailing in the Bolivian Altiplano (Garcia et al., 2003; Geerts et al., 2006a). Quinoa is a very drought resistant crop (Vacher, 1998; Jensen et al., 2000; Winkel et al., 2002) and one of the reported mechanisms of drought escape is its flexible phenology and growth cycle length (Jacobsen et al., 2003; Garcia, 2003). Whereas the effect of photoperiod and temperature (Bertero et al., 1999a,b) and even radiation (Bertero, 2001) on the development of quinoa was profoundly studied, the effect of drought stress on the phenology was not quantified before in field conditions. However, a better knowledge of the phenological development of quinoa under these conditions is desirable, since a varying cropping cycle length hinders a good planning of agricultural practices and labor. Further-on, a stretching of the crop cycle will strongly increase the risk of frost in the late season as it occurs in the Bolivian Altiplano (Geerts et al., 2006a).

\section{Methodology}

Field experiments were carried out during the growing seasons of 2005-2006 and 2006-2007 in Patacamaya $\left(17^{\circ} 16^{\prime} \mathrm{S} ; 67^{\circ} 57^{\prime} \mathrm{W}\right.$; 3,799 m.a.s.l.), located in the semi-arid, central Bolivian Altiplano. The experimental fields were representative for local agricultural and fertility conditions in the Bolivian Altiplano. Three different irrigation treatments were applied in both years (Table 1). In 20052006, the treatments consisted of rainfed cultivation (R), full irrigation (FI) throughout the complete crop cycle, and deficit irrigation (DI) with irrigation limited to drought sensitive phenological stages (Geerts et al., 2006b). In 2006-2007, three different DI strategies (DI 1, DI 2 and DI 3) were applied. The variety 'Santa Maria' was sown with a density of $8 \mathrm{~kg}$ of seeds/ha in both years and irrigation was applied via short furrows. To study the effect of drought on phenological development, quinoa was sown on three different dates in 2005-2006 (Table 1). The variety 'Santa Maria' is a commercial cultivar, with an average growth cycle length of 150 days, relatively large, sweet, and white seeds, moderate tolerance to pests, diseases and droughts and high tolerance to frost $\left(-5^{\circ} \mathrm{C}\right)$ during flowering (IBTA, 1996).
Meteorological data (maximum and minimum air temperature, maximum and minimum relative humidity, mean wind speed and total solar radiation) were recorded daily in an automatic weather station next to the fields. Reference evapotranspiration $\left(\mathrm{ET}_{0}\right)$ was calculated on a daily basis using the FAOPenman-Monteith equation (Allen et al., 1998). Soil water content at field capacity and wilting point required for the estimation of the total available soil water (TAW) were respectively 25.1 and $6.3 \mathrm{vol} \%$ in the $2005-2006$ fields and 22.9 and $5.3 \mathrm{vol} \%$ in the 2006-2007 fields. They were derived with the pressure plate method on undisturbed soil samples. Soil water contents were monitored weekly with a gravimetrical procedure (2005-2006) or a TDR soil moisture probe (2006-2007). Phenological stages of emergence, first anthesis and physiological maturity were observed according to the indications of Espindola (1980) for quinoa. For each of the treatments, the time from sowing to anthesis (TA) and from sowing to physiological maturity (TM) was expressed in calendar days and in GDD. GDD sums were calculated according to McMaster and Wilhelm (1997) with a base temperature of $1{ }^{\circ} \mathrm{C}$ (Bois et al., 2006). To describe crop growth, the green leaf area index (LAI) was measured every 2 weeks using the AccuPAR LP80 radiation interception meter. To account for crop heterogeneity, the interception measurements were repeated 12 times per experimental unit (pseudo-repetitions (Hurlbert, 1984)). To account for experimental heterogeneity, the measurements were repeated in each of the blocks (repetitions) of the experimental designs.

Actual crop transpiration $\left(T_{\mathrm{a}}\right)$ was calculated from a daily soil water balance, in which the root zone is considered as a reservoir. Water is supplied to the reservoir by rainfall and irrigation. Due to the presence of a hard pan at $0.35 \mathrm{~m}$ soil depth, zero drainage could be assumed at the bottom boundary of the shallow root zone (Garcia, 1991). In this way, water is only extracted from the reservoir by evapotranspiration. A Ritchie type approach (Ritchie, 1972), parameterized for the local soil physical conditions (Geerts et al., 2008a), was used to estimate the actual soil evaporation after wetting of the soil surface by rainfall or irrigation. As a reference, crop transpiration for well watered conditions $\left(T_{\mathrm{c}}\right)$ was assessed by the $K_{\mathrm{c}} \times \mathrm{ET}_{0}$ approach (Allen et al., 1998). As long as the readily available soil water (RAW) is not depleted from the root zone, $T_{\mathrm{a}}$ is equal to $T_{\mathrm{c}}$. RAW was taken as $61 \%$ of TAW (Garcia, 2003). Once RAW is depleted the soil water content in the root zone drops below a threshold level and drought stress occurs $\left(T_{\mathrm{a}}<T_{\mathrm{c}}\right)$. The water stress factor $K_{\mathrm{s}}$, describes this effect of water stress on the $T_{\mathrm{a}}$ of a plant in function of TAW. When the soil water content is within the limits of RAW, $K_{\mathrm{s}}$ is 1 and $T_{\mathrm{c}}$ is equal to $T_{\mathrm{a}}$. After RAW is depleted, $K_{\mathrm{s}}$ gradually decreases to a zero value at wilting point. $T_{\mathrm{a}}$

Table 1

Applied irrigation and specifications of the experimental fields under rainfed conditions (R), deficit irrigation (DI) or with full irrigation (FI)

\begin{tabular}{|c|c|c|c|}
\hline Treatment number & Irrigation treatment & Time of additional irrigation application ${ }^{a}$ & Sowing date \\
\hline \multicolumn{4}{|c|}{ 2005-2006 crop season } \\
\hline $\mathrm{T} 1$ & FI & Throughout season & 7 October 2005 \\
\hline $\mathrm{T} 2$ & DI & $\mathrm{E}, \mathrm{F}, \mathrm{G}$ & 7 October 2005 \\
\hline T3 & $\mathrm{R}$ & None & 7 October 2005 \\
\hline $\mathrm{T} 4$ & FI & Throughout season & 21 October 2005 \\
\hline T5 & DI & E, F, G & 21 October 2005 \\
\hline T6 & $\mathrm{R}$ & None & 21 October 2005 \\
\hline T7 & FI & Throughout season & 9 November 2005 \\
\hline T8 & DI & E, F, G & 9 November 2005 \\
\hline T9 & $\mathrm{R}$ & None & 9 November 2005 \\
\hline \multicolumn{4}{|c|}{ 2006-2007 crop season } \\
\hline $\mathrm{T} 1$ & DI & E & 22 October 2006 \\
\hline $\mathrm{T} 2$ & DI & E, F, G & 22 October 2006 \\
\hline T3 & DI & E, PF, F, G & 22 October 2006 \\
\hline
\end{tabular}

\footnotetext{
${ }^{a}$ E: establishment; PF: pre-flowering; F: flowering; G: early grain filling.
} 
is then obtained by multiplying $T_{\mathrm{c}}$ by the actual value of the water stress factor $K_{\mathrm{s}}$ (for calculation details, see Allen et al. (1998)).

Daily values for $K_{\mathrm{c}}$ were obtained by assuming the proportionality between $K_{\mathrm{c}}$ and the green canopy cover (CC) as described by Steduto et al. (2006) and Raes et al. (2006). The default value of 1.1 for the proportional factor $\left(K_{\mathrm{c}, \mathrm{top}}\right)$ was considered. To derive green canopy cover from the measured green LAI a Ritchie type of equation (Belmans et al., 1983) was used:

$\mathrm{CC}=1-f \mathrm{e}^{-c \mathrm{LAI}}$

where CC is the canopy cover (fraction) and LAI the leaf area index. By comparing measured CC and LAI values in the experimental fields of Patacamaya in 2005-2006, Eq. (1) was calibrated for quinoa under row sowing with empirical factors $c$ of 0.7 and $f$ of 1 .

To evaluate the effect of drought stress before anthesis on crop development, the drought stress during the first 60 days after sowing (DAS) was assessed with different stress indicators. The limit of 60 DAS was selected since the earliest observed time of anthesis of the considered quinoa variety occurred at 66 DAS. In order for the drought stress indicator and the derived model to be as generic as possible, the time of 60 DAS was selected for future crop modeling purposes, instead of considering the total water stress until the (variable) time of flowering.

The considered stress indicators were:

- the number of days that RAW was not completely depleted from the root zone $\left(\sum D\right)$;

- the average relative transpiration $\left(T_{\mathrm{a}} / T_{\mathrm{c}}\right)$;

- the sum of daily actual transpiration, standardized for reference evapotranspiration $\left(\sum\left(T_{\mathrm{a}} / \mathrm{ET}_{0}\right)\right)$. This criterion follows the philosophy of Steduto et al. (2007) on the conservative behavior of biomass water productivity.

Results of the 9 treatments of the growing season 2005-2006 were used to establish the regressions between the different drought stress indicators and TA in calendar days and GDD. Results of the three treatments of 2006-2007 were used to validate the obtained regressions. As an extension, regressions were derived between the drought stress indicators and TM. Goodness of fit of the derived relations was assessed on the basis of the coefficient of determination $\left(R^{2}\right)$, the root mean squared error (RMSE) in absolute value or relative to the mean, and the Nash efficiency (EF) as described by Loague and Green (1991).

\section{Results and discussion}

\subsection{Correlation between drought stress and time to anthesis}

Comparison of the measured soil water content (SWC) with the simulated values showed high values for goodness of fit. $R^{2}$ values ranged from 0.59 to 0.85 and Nash efficiencies were limited between 0.46 and 0.81 , with exception of one of the treatments (T1, 2005-2006) with somewhat lower goodness of fit $\left(R^{2} 0.40\right.$; Nash efficiency 0.32 ). The good agreement signifies that estimates of $T_{\mathrm{a}}$ and of the relative transpiration $\left(T_{\mathrm{a}} / T_{\mathrm{c}}\right)$ can be regarded as reliable. Table 2 presents the average $T_{a} / T_{c}$ for the different treatments for the period until 60 DAS and for the total growing period. These values of relative transpiration reflect the drought stress that occurred in each treatment as modeled with the soil water balance. Drought stress that occurred in the FI treatments is most likely due to the limited storage capacity of the shallow root zone.

With reference to the fully irrigated fields, drought stress in the various treatments increased TA up to 30 days, or up to 300 GDD.
Table 2

Relative transpiration $\left(T_{\mathrm{a}} / T_{\mathrm{c}}\right)$ for the different treatments for the first 60 days after sowing and for the complete cropping cycle

\begin{tabular}{|c|c|c|c|}
\hline \multirow[t]{2}{*}{ Number } & \multirow[t]{2}{*}{ Treatment } & \multicolumn{2}{|c|}{$T_{\mathrm{a}} / T_{\mathrm{c}}:$ relative transpiration (\%) } \\
\hline & & Until 60 DAS & Until harvest \\
\hline \multicolumn{4}{|c|}{ 2005-2006 crop season } \\
\hline $\mathrm{T} 1$ & FI & 87 & 80 \\
\hline $\mathrm{T} 2$ & DI & 68 & 75 \\
\hline T3 & $\mathrm{R}$ & 53 & 57 \\
\hline $\mathrm{T} 4$ & FI & 81 & 86 \\
\hline T5 & DI & 67 & 72 \\
\hline T6 & $\mathrm{R}$ & 30 & 45 \\
\hline $\mathrm{T} 7$ & FI & 85 & 80 \\
\hline T8 & DI & 70 & 68 \\
\hline T9 & $\mathrm{R}$ & 55 & 54 \\
\hline \multicolumn{4}{|c|}{ 2006-2007 crop season } \\
\hline $\mathrm{T} 1$ & DI & 68 & 61 \\
\hline $\mathrm{T} 2$ & DI & 71 & 71 \\
\hline T3 & DI & 76 & 74 \\
\hline
\end{tabular}

Fig. 1 and Table 3 present the regression relations between the 3 considered drought stress indicators and TA. All 3 drought stress indicators, $\sum D, T_{\mathrm{a}} / T_{\mathrm{c}}$ and $\sum\left(T_{\mathrm{a}} / \mathrm{ET}_{0}\right)$, gave excellent correlations with phenological development.

In general it appears that correlations between drought stress indicators and phenological development are significant for calendar time as well as for thermal time accumulation. This makes the obtained correlations useful for models that simulate phenological development with calendar days or GDD. However, the validation of the obtained correlations with the results of the 2006/2007 experiment (Fig. 1, triangles) indicates that the correlations are better for thermal time accumulation than for calendar days (relative RMSE of 2-3\% for thermal time versus 7-8\% for calendar days, for all drought stress indicators). This is probably due to the influence of a warm phase (El Niño event) of the El Niño Southern Oscillation (Vuille, 1999; Garreaud et al., 2003) in the growing season of 2006-2007, resulting in higher temperatures in the Bolivian Altiplano and an acceleration of crop development.

Although the three drought stress indicators $\sum D, T_{\mathrm{a}} / T_{\mathrm{c}}$ and $\sum\left(T_{\mathrm{a}} / \mathrm{ET}_{0}\right)$ are highly correlated with TA (Table 3 ), preference is given to $\sum\left(T_{\mathrm{a}} / \mathrm{ET}_{0}\right)$ as indicator, because:

- the discontinuous nature of the first indicator $\left(\sum D\right)(1 / 0)$ may result in over or under-weighing of events where SWC is close to the threshold level;

- the logarithmic relationship of $\sum\left(T_{\mathrm{a}} / \mathrm{ET}_{0}\right)$ as compared to $T_{\mathrm{a}} / T_{\mathrm{c}}$ is better to describe the increasingly important effect of drought stress on the phenological development when $T_{\mathrm{a}}$ becomes very small. Moderate (DI) or near to zero (FI) drought stress have both very small effects on phenological development, whereas elevated drought stress $(R)$ results in a substantial increase of TA;

- the direct normalization of the indicator $\sum\left(T_{\mathrm{a}} / \mathrm{ET}_{0}\right)$ for climate $\left(\mathrm{ET}_{0}\right)$ makes it also applicable in regions with a different evaporating power of the atmosphere;

- as a result of the conservative behavior of biomass water productivity (Steduto et al., 2007), $\sum\left(T_{\mathrm{a}} / \mathrm{ET}_{0}\right)$ is proportional with the total above ground dry biomass at 60 DAS which makes that the indicator can be observed on-site.

From Fig. 1, one could pose the hypothesis of a certain drought stress threshold, below which there is no effect on quinoa phenology. This could theoretically give rise to a broken stick type of curve. As this threshold is nevertheless difficult to derive, and as this threshold might have a certain error range, a logarithmic model, with a relatively horizontal shape for zero to 
(a)

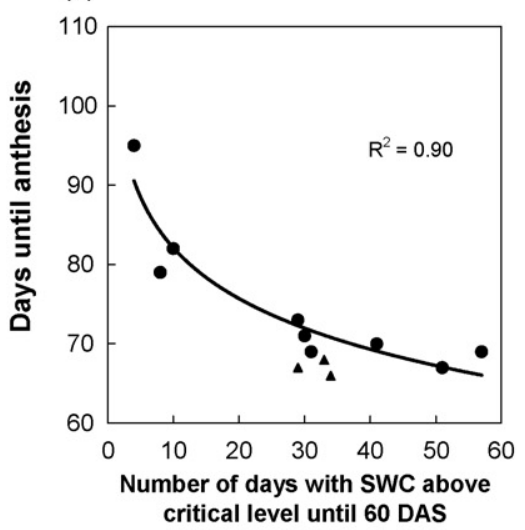

(c)

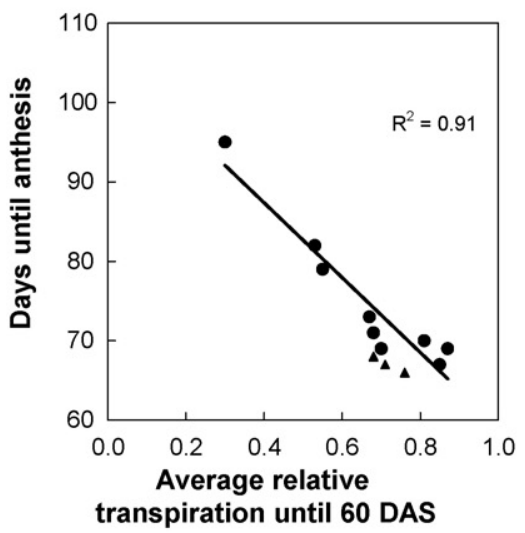

(e)

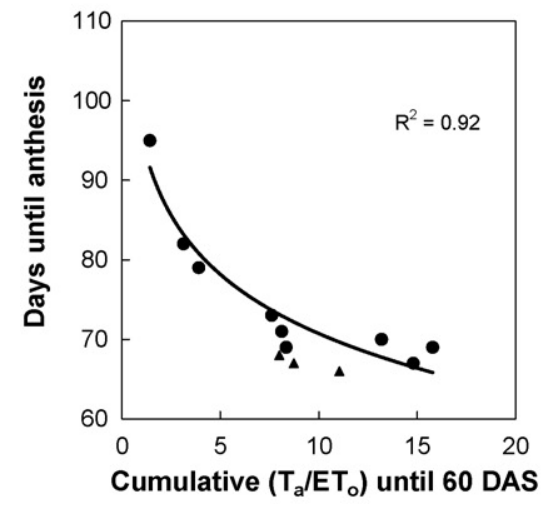

(b)

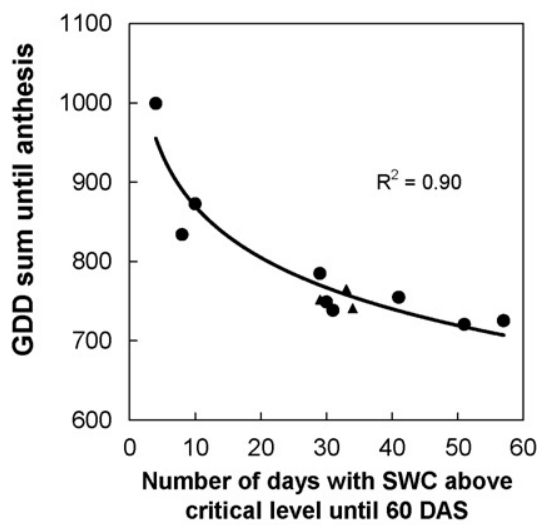

(d)

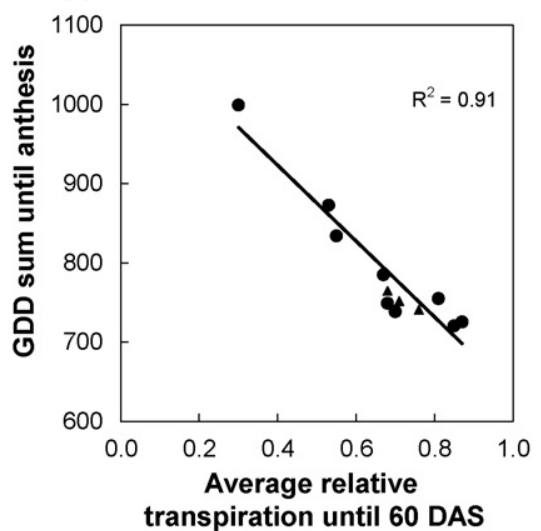

(f)

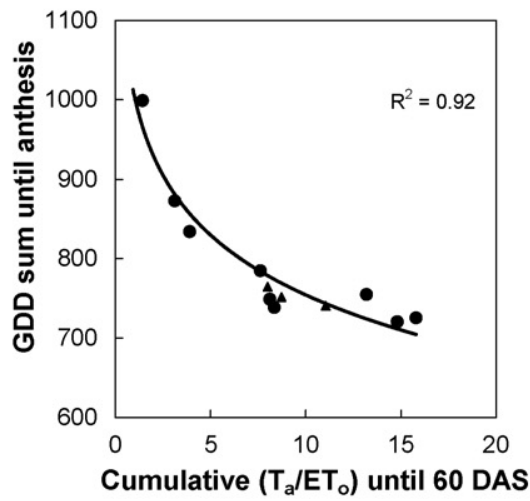

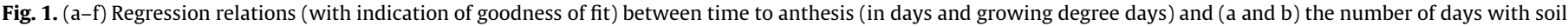

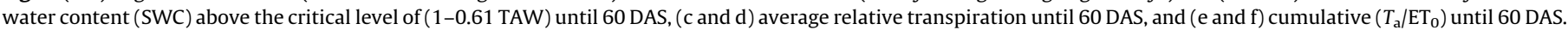
Circles refer to treatments of 2005-2006 used to establish the regressions, and triangles to treatments of 2006-2007 used for validation.

Table 3

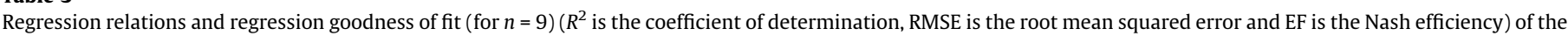

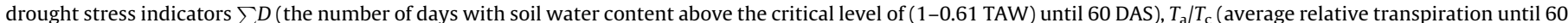

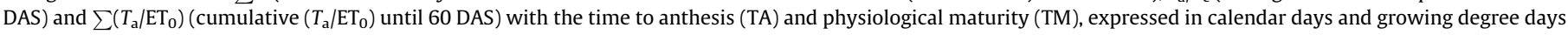

\begin{tabular}{|c|c|c|c|c|}
\hline Drought stress indicator & Regression relation (days) & $R^{2}$ & RMSE & $\mathrm{EF}$ \\
\hline$\sum D$ & $\mathrm{TA}=103.3-9.2 \operatorname{Ln}\left(\sum D\right)$ & 0.90 & 2.7 & 0.90 \\
\hline$T_{\mathrm{a}} / T_{\mathrm{c}}$ & $\mathrm{TA}=106.2-47.2\left(T_{\mathrm{a}} / T_{\mathrm{c}}\right)$ & 0.91 & 2.6 & 0.91 \\
\hline$\sum\left(T_{\mathrm{a}} / \mathrm{ET}_{0}\right)$ & $\mathrm{TA}=95.5-10.7 \operatorname{Ln}\left(\sum\left(T_{\mathrm{a}} / \mathrm{ET}_{0}\right)\right)$ & 0.92 & 2.3 & 0.92 \\
\hline \multirow[t]{2}{*}{$\sum\left(T_{\mathrm{a}} / \mathrm{ET}_{0}\right)$} & $\mathrm{TM}=186.4-14.18 \operatorname{Ln}\left(\sum\left(T_{\mathrm{a}} / \mathrm{ET}_{0}\right)\right)$ & 0.89 & 3.7 & 0.89 \\
\hline & Regression relation (growing degree days) & & & \\
\hline$\sum \mathrm{D}$ & $\mathrm{TA}=1084.6-93.3 \operatorname{Ln}\left(\sum D\right)$ & 0.90 & 27.8 & 0.90 \\
\hline$T_{\mathrm{a}} / T_{\mathrm{c}}$ & $\mathrm{TA}=1114.5-478.2\left(\mathrm{~T}_{\mathrm{a}} / \mathrm{T}_{\mathrm{c}}\right)$ & 0.91 & 26.5 & 0.91 \\
\hline$\sum\left(T_{\mathrm{a}} / \mathrm{ET}_{0}\right)$ & $\mathrm{TA}=1005.1-108.9 \operatorname{Ln}\left(\sum\left(T_{\mathrm{a}} / \mathrm{ET}_{0}\right)\right)$ & 0.92 & 24.0 & 0.92 \\
\hline$\sum\left(T_{\mathrm{a}} / \mathrm{ET}_{0}\right)$ & $\mathrm{TM}=1916.9-141.35 \operatorname{Ln}\left(\sum\left(T_{\mathrm{a}} / \mathrm{ET}_{0}\right)\right)$ & 0.89 & 36.9 & 0.89 \\
\hline
\end{tabular}


moderate stress levels, is a more continuous way to evaluate the effect of pre-anthesis drought stress on crop phenology.

The proposed relations should be checked for quinoa varieties other than 'Santa Maria' since in the more arid south of the Bolivian Altiplano, quinoa varieties with an apparent longer cycle are often cultivated. There the considered 60 DAS period for the calculation of the drought stress indicators might need to be adjusted. However, the results of the field experiments reported in this paper might suggest that the sometimes observed longer crop cycle length in the South could partly be the result of stronger drought stress encountered in this more arid region. Although genotypic differences in time to physiological maturity under no-stress conditions certainly exist (Bertero et al., 2004), even the standard cropping cycle length as provided by certified seed sellers might sometimes already incorporate normal drought stress occurrence during vegetative stages.

\subsection{Extension of the correlation to time to physiological maturity}

As a possible extension to the proposed model, the correlation between the drought stress indicators and TM was indicatively assessed. Fig. 2 and Table 3 present these correlations for the stress indicator $\sum\left(T_{\mathrm{a}} / \mathrm{ET}_{0}\right)$ until 60 DAS. Correlations of the stress indicators were lower with TM than with TA, due to the lower goodness of fit for TM of the 3 validation fields of 2006-2007 (compare Fig. 2 and Fig. 1, triangles). The lower correlations with TM for the validation fields suggest some confounding effect of the exceptional weather conditions after anthesis in these validation experiments. In fact, preliminary findings (Huiza Laura, 1994; Garcia, 2003) showed that post-anthesis drought can decrease TM, an effect opposite to that of pre-anthesis drought. For the 20052006 experiments, correlations of stress indicators with TA and with TM showed a similar goodness of fit because of a relatively good rainfall distribution after anthesis in this rainy season. In this way, phenological development in these experiments was only affected by pre-anthesis drought. In the 2006-2007 trials, on the contrary, some drought stress as well as serious water logging occurred after anthesis, causing noise in the correlation with TM and impeding the quantification of the additional effect of postanthesis drought. The results of this study (2006-2007) and of Huiza Laura (1994) and Garcia (2003) however indicate that the effect of post-anthesis drought is smaller than the increasing effect of pre-anthesis drought on the total crop cycle length. It is clear that the effect of post-anthesis water stress on phenological development should be quantified in separate experiments to derive a better model for the effect of water stress on the total length of the cropping cycle.

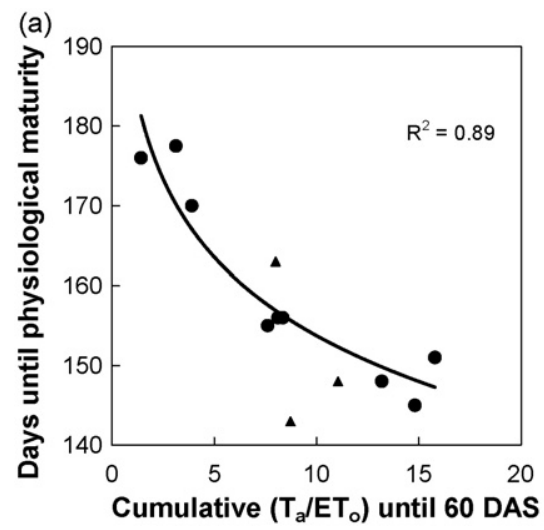

The indicator $\sum\left(T_{\mathrm{a}} / \mathrm{ET}_{0}\right)$, and in extension the observable above ground dry biomass at 60 DAS (Steduto et al., 2007) can thus be an indicator of the expected length of the growing season (TM), but only if post-anthesis drought stress or water logging is limited. If a low above ground biomass at 60 DAS is observed in the field, an increase of the growth cycle is very likely to be expected. Moderate above ground biomass at 60 DAS should however not be considered as an indicator of a strong increase of the crop cycle, because of the logarithmic nature of the correlation (Figs. 1e and $\mathrm{f}$ and 2).

\subsection{Discussion on the mechanism and link with other crops}

Although it needs further corroboration, the described effect of severe pre-anthesis drought (pronounced development deceleration), as well as post-anthesis drought (slight acceleration of physiological maturity) could on the one hand be regarded as adaptive mechanisms of the quinoa plant to avoid droughts during flowering (by postponing anthesis) and grain filling (by accelerating maturity). On the other hand, it has been established that for other crops timing of flowering is strongly related to growth as such (Gross, 1981; Hirose and Kachi, 1982; Wery, 2005), also in the frame of evolutionary fitness (Metcalf et al., 2003). This suggests that the effect of drought stress on quinoa phenology is indirect via growth. So as drought stress retards growth in quinoa (Geerts et al., $2006 \mathrm{~b}$ ), decelerated growth could be part of the explanation of the delayed flowering (refer also to the 3rd drought stress indicator that is closely related to above-ground biomass growth). This is linked with the division of crop species in so-called determinate and indeterminate crops regarding their source-sink relations during phenological development (Hay and Walker, 1989; Reekie, 1997; Azam-Ali and Squire, 2002). Notwithstanding the value of the posed hypothesis, it is known from field experiences that a lot of quinoa varieties are able to produce some yield, irrespective of a certain critical plant size for panicle development. That this occurs after a considerable delay in flowering should hereby be taken into account. This indicates that although a clear effect of drought stress on phenology could be demonstrated, the underlying mechanism still needs to be investigated further, preferably in cultivars originating from different latitudes (Bertero, 2001) and in the frame of dividing between evolutionary (long term) and mere physiological (short term) phenological adaptation (Hodges, 1991; Blum, 1996).

Though comparison of quinoa with other crops is difficult due to the particular combination of high radiation, frost and aridity in the Andean highlands, phenological responses of quinoa to dry spells show some similarities with those of grain crops in warm

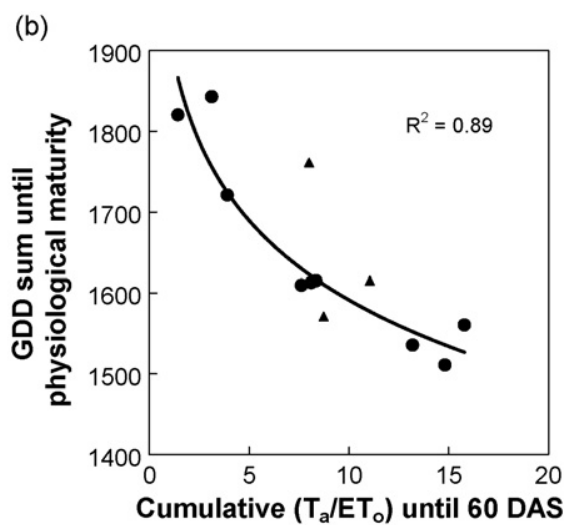

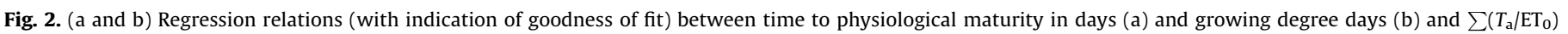

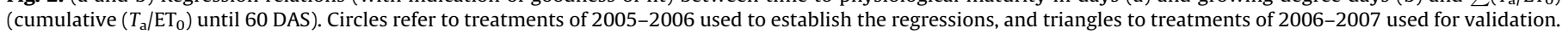


semi-arid tropics. Donatelli et al. (1992) report that for sorghum, relative thermal time increased from a stress threshold of 55\% of relative transpiration onward. In this study, the response of quinoa appeared to be more continuous, albeit it with an important logarithmic shape. Tsuda (1986) also mentions a threshold of critical leaf water potential, above which no effect on rice and sorghum phenology could be distinguished. Further-on, they mention a linear increase in timing of panicle exertion with increasing water stress imposed just after floral initiation. Farré and Faci (2006) report a delay in flowering ( 7 and 17 days) and maturity (5 and 12 days) for respectively sorghum and maize due to pre-anthesis water deficit. Abrecht and Carberry (1993) also mention delayed flowering in maize under drought stress, but only for 4 days. McMaster and Wilhelm (2003) on the other hand report the hastening effect of drought stress on phenological development of wheat and barley, for the timing of flowering as well as for the time to physiological maturity (McMaster, 2004), but state that the modeling of this effect is hindered by important genotype by environment interactions, which was later on further demonstrated (McMaster et al., 2005) and also mentioned for quinoa (Bertero et al., 2004). The comparisons with other crops indicate that the delayed flowering in response to pre-anthesis drought stress as observed for quinoa is not exceptional in its existence, but more in its magnitude (strong logarithmic relation).

\subsection{Practical application}

Deficit irrigation (DI) is a practice that is worthwhile to apply for quinoa in dry regions (Garcia, 2003; Geerts et al., 2008a,b). In general, Oweis and Hachum (2006) mention the substantial increase in water productivity of grain and legume crops if DI is applied in a sound way in dry regions where water and not land is the limiting factor. Oweis et al. (1998) and Oweis and Hachum (2001) point out the higher level of control over sowing date and crop cycle (higher independence from climate) as additional advantages of DI. Debaeke and Aboudrare (2004) on the other hand summarize that a farmer should combine different management strategies, such as DI, to cope with drought and to increase water productivity. They mention that among others, the seasonal water use pattern should be optimized between pre- and post-anthesis. This was already indicated for quinoa by Geerts et al. (2008a), who demonstrated a significant relation between this pattern and the water use efficiency.

As shown in this study, quinoa under DI still has a close to normal TA and TM. This is mainly due to the logarithmic nature of the relation between drought stress and the corresponding increase of the cropping cycle. On top of a substantial increase of water productivity of quinoa by DI (Geerts et al., 2008a), the practice of DI also allows a better planning of labor and a concentration of the growing season within the optimal window of frost free days. Moreover, it is demonstrated in this study that FI is redundant as compared to DI, even for achieving a better agricultural planning.

\section{Conclusion}

Severe drought stress up to anthesis can result in a considerable increase of the time to anthesis and to physiological maturity. Moderate drought stress is not likely to cause this effect. This demonstrates the high phenological plasticity of quinoa var. 'Santa Maria' as a drought escape mechanism. Although no complete drought stress-thermal time interaction model was presented for quinoa, quinoa phenology in response to pre-anthesis droughts was quantified for field conditions. The proposed model should be validated for other quinoa varieties and other regions and should be improved by also considering post-anthesis drought. The obtained correlations can be a substantial improvement for the management of quinoa in the region and for the simulation of quinoa crop development. The general approach and the drought stress indicators presented in this paper might even be valuable in describing phenological development of other drought tolerant crops with high phenological flexibility.

\section{Acknowledgements}

Research funded by a Ph.D. grant of the Flemish Interuniversity Council (VLIR). The research is carried out in Bolivia in the frame of the VLIR Own Initiative Project QuinAgua, scientific collaboration between K.U. Leuven and the Universidad Mayor de San Andres. Our debt of gratitude is extended to the people of the ex-IBTA (UMSA-station) in Patacamaya, Bolivia. We highly appreciate the valuable comments of the anonymous reviewers.

\section{References}

Abrecht, D.G., Carberry, P.S., 1993. The influence of water deficit prior to tassel initiation on maize growth, development and yield. Field Crops Res. 31, 55-69. Adam, N.R., Dierig, D.A., Coffelt, T.A., Wintermeyer, M.J., Mackey, B.E., Wall, G.W., 2007. Cardinal temperatures for germination and early growth of two Lesquerella species. Ind. Crops Prod. 25, 24-33.

Al-Ahmadi, M.J., Kafi, M., 2007. Cardinal temperatures for germination of Kochia scoparia (L.). J. Arid Environ. 68, 308-314.

Allen, R.G., Pereira, L.S., Raes, D., Smith, M., 1998. Crop evapotranspiration-guidelines for calculating crop water requirements. FAO Irrigation and Drainage Paper 56. FAO, Rome, Italy.

Azam-Ali, S.N., Squire, G.R., 2002. Principles of Tropical Agronomy. CABI Publishing, Wallingford, UK.

Belmans, C., Wesseling, J.G., Feddes, R.A., 1983. Simulation model of the water balance of a cropped soil: SWATRE. J. Hydrol. 63, 271-286.

Bertero, H.D., 2001. Effects of photoperiod, temperature and radiation on the rate of leaf appearance in quinoa (Chenopodium quinoa Willd.) under field conditions. Ann. Bot. 87, 495-502.

Bertero, H.D., King, R.W., Hall, A.J., 1999a. Photoperiod-sensitive development phases in quinoa (Chenopodium quinoa Willd.). Field Crops Res. 60, 231-243.

Bertero, H.D., King, R.W., Hall, A.J., 1999b. Modelling photoperiod and temperature responses of flowering in quinoa (Chenopodium quinoa Willd.). Field Crops Res. 63, 19-34.

Bertero, H.D., de la Vega, A.J., Correa, G., Jacobsen, S.E., Mujica, A., 2004. Genotype and genotype-by-environment interaction effects for grain yield and grain size of quinoa (Chenopodium quinoa Willd.) as revealed by pattern analysis of international multi-environment trials. Field Crops Res. 89, 299-318.

Bhargava, A., Shukla, S., Ohri, D., 2006. Chenopodium quinoa-an Indian perspective. Ind. Crops Prod. 23, 73-87.

Blum, A., 1996. Crop responses to drought and the interpretation of adaptation. Plant Growth Regul. 20, 135-148.

Bois, J.F., Winkel, T., Lhomme, J.P., Raffaillac, J.P., Rocheteau, A., 2006. Response of some Andean cultivars of quinoa (Chenopodium quinoa Willd.) to temperature: effects on germination, phenology, growth and freezing. Eur. J. Agron. 25, 299308.

Brisson, N., Gary, C., Justes, E., Roche, R., Mary, B., Ripoche, D., Zimmer, D., Sierra, J., Bertuzzi, P., Burger, P., Bussière, F., Cabidoche, Y.M., Cellier, P., Debaeke, P., Gaudillère, J.P., Hénault, C., Maraux, F., Seguin, B., Sinoquet, H., 2003. An overview of the crop model STICS. Eur. J. Agron. 18, 309-332.

Comai, S., Bertazzo, A., Bailoni, L., Zancato, M., Costa, C.V.L., Allegri, G., 2007. The content of proteic and nonproteic (free and protein-bound) tryptophan in quinoa and cereal flours. Food Chem. 100, 1350-1355.

Debaeke, P., Aboudrare, A., 2004. Adaptation of crop management to water-limited environments: water limited agriculture. Eur. J. Agron. 21, 433-446.

Donatelli, M., Hammer, G.L., Vanderlip, R.L., 1992. Genotype and water limitation effects on phenology, growth and transpiration efficiency in grain sorghum. Crop Sci. 32, 781-786

Eitzinger, J., Trnka, M., Hösch, J., Zalud, J., Dubrovsky, M., 2004. Comparison of CERES WOFOST and SWAP models in simulating soil water content during growing season under different soil conditions. Ecol. Model 171, 223-246.

Espindola, G., 1980. Estudio de componentes directos e indirectos del rendimiento en quinua (Chenopodium quinoa Willd.). Tesis de Grado, Facultad de Ciencias Agricolas y Pecuarias 'Martin Cardenas', Cochabamba, Bolivia.

Farré, I., Faci, J.M., 2006. Comparative response of maize (Zea mays L,) and sorghum (Sorghum bicolor L. Moench) to deficit irrigation in a Mediterranean environment. Agric. Water Manage. 83, 135-143.

Garcia, M., 1991. Comportamiento hídrico de dos variedades de quinoa en respuesta a la sequía. Dissertation presented for the Degree of Agronomic Engineer. Universidad Mayor de San Andres, La Paz, Bolivia. 
Garcia, M., 2003. Agroclimatic study and drought resistance analysis of quinoa for an irrigation strategy in the Bolivian Altiplano. Dissertationes de Agricultura, Faculty of Applied Biological Sciences, K.U. Leuven, Belgium, p. 556

Garcia, M., Raes, D., Jacobsen, S.E., 2003. Evapotranspiration analysis and irrigation requirements of quinoa (Chenopodium quinoa) in the Bolivian highlands. Agric. Water Manage. 60, 119-134.

Garreaud, R., Vuille, M., Clement, A.C., 2003. The climate of the Altiplano: observed current conditions and mechanisms of past changes. Palaeogeogr. Palaeocl. 194, $5-22$.

Geerts, S., Raes, D., Garcia, M., Del Castillo, C., Buytaert, W., 2006a. Agro-climatic suitability mapping for crop production in the Bolivian Altiplano: a case study for quinoa. Agric. Forest Meteorol. 139, 399-412.

Geerts, S., Mamani, R.S., Garcia, M., Raes, D., 2006b. Response of quinoa (Chenopodium quinoa Willd.) to differential drought stress in the Bolivian Altiplano: towards a deficit irrigation strategy within a water scarce region. In: Proceedings of the 1st International Symposium on Land and Water Management for Sustainable Irrigated Agriculture, Adana, Turkey. CD-rom.

Geerts, S., Raes, D., Garcia, M., Vacher, J., Mamani, R., Mendoza, J., Huanca, R., Morales, B., Miranda, R., Cusicanqui, J., Taboada, C., 2008a. Introducing deficit irrigation to stablize yields of quinoa (Chenopodium quinoa Willd.). Eur. J. Agron. $28,427-436$

Geerts, S., Raes, D., Garcia, M., Condori, O., Mamani, J., Miranda, R., Cusicanqui, J., Taboada, C., Vacher, J., 2008b. Could deficit irrigation be a sustainable practice for quinoa (Chenopodium quinoa Willd.) in the Southern Bolivian Altiplano? Agric. Water Manage. 95, 909-917.

Gross, K.L., 1981. Predictions of fate from rosette size in four "biennial" plant species: Verbascum thapsus, Oenothera biennis, Daucus carota, and Tragopogon dubius. Oecologia, 48, 209-213.

Hay, R.K.M., Walker, J., 1989. An Introduction to the Physiology of Crop Yield. Longman Scientific \& Technical, Essex, England.

Hirose, T., Kachi, N., 1982. Critical plant size for flowering in biennials with special reference to their distribution in a sand dune system. Oecologia, 55, 281-284.

Hodges, T., 1991. Chapter 3: temperature and water stress effects on phenology. In: Hodges, T. (Ed.), Predicting Crop Phenology. CRC Press, Boca Raton, FL, USA, pp. $7-14$.

Hoogenboom, G., 2000. Contribution of agrometeorology to the simulation of crop production and its applications. Agric. Forest Meteorol. 103, 137-157.

Howell, T., 2001. Enhancing water use efficiency in irrigated agriculture. Agron. J. 93, 281-289.

Huiza Laura, Z., 1994. Efecto del deficit hidrico a marchitez intensa sobre el ritmo de crecimiento de la quinua (Chenopodium quinoa Willd.). Tesis de grado de la Facultad de Agronomía, UMSA, La Paz, Bolivia.

Hurlbert, S.H., 1984. Pseudoreplication and the design of ecological field experiments. Ecol. Monogr. 54, 187-211.

Instituto Boliviano de Tecnología en Agricultura (IBTA), 1996. Catálogo de variedades mejoradas de quinua y recomendaciones para producción y uso de semilla certificada. Secretaría Nacional de Agricultura y Ganadería, La Paz, Bolivia. Boletín No 2.

Jacobsen, S.E., 2003. The Worldwide Potential for Quinoa (Chenopodium quinoa Willd.). Food Rev. Int. 19, 167-177.

Jacobsen, S.E., Mujica, A., Jensen, C.R., 2003. The Resistance of Quinoa (Chenopodium quinoa Willd.) to Adverse Abiotic Factors. Food Rev. Int. 19, 99-109.

Jensen, C.R., Jacobsen, S.-E., Andersen, M.N., Núńez, N., Andersen, S.D., Rasmussen, L., Mogensen, V.O., 2000. Leaf gas exchange and water relation characteristics of field quinoa (Chenopodium quinoa Willd.) during soil drying. Eur. J. Agron. 13, 11-25.

Loague, K., Green, R.E., 1991. Statistical and graphical methods for evaluating solute transport models: overview and application. J. Contam. Hydrol. 7, 51-73.

Madariaga, F.J., Knott, J.E., 1951. Temperature summations in relation to lettuce growth. Proc. Am. Soc. Hortic. Sci. 58, 147-152.

McMaster, G.S., 2004. Simulating crop phenology. In: Fischer, T. et al. (Eds.), New directions for a diverse planet: Proceedings for the 4th International Crop Science Congress. Online at http://www.cropscience.org.au/icsc2004/poster/ 2/8/607_mcmaster.htm.

McMaster, G., Smika, D.E., 1988. Estimation and evaluation of winter wheat phenology in the central great plains. Agric. Forest Meteorol. 43, 1-18.

McMaster, G.S., Wilhelm, W.W., 1997. Growing degree-days: one equation, two interpretations. Agric. Forest Meteorol. 87, 291-300.
McMaster, G.S., Wilhelm, W.W., 2003. Phenological responses of wheat and barley to water and temperature: improving simulation models. J. Agric. Sci. 141, 129147.

McMaster, G.S., Wilhelm, W.W., Frank, A.B., 2005. Developmental sequences for simulating crop phenology for water-limiting conditions. Aust. J. Agric. Res. 56 1277-1288.

Metcalf, J.C., Rose, K.E., Rees, M., 2003. Evolutionary demography of monocarpic perennials. Trends Ecol. Evol. 18, 471-480.

Oweis, T., Hachum, A., 2001. Reducing peak supplemental irrigation demand by extending sowing dates. Agric. Water Manage. 50, 109-123.

Oweis, T., Hachum, A., 2006. Water harvesting and supplemental irrigation for improved water productivity of dry farming systems in West Asia and North Africa: special issue on water scarcity: challenges and opportunities for crop science. Agric. Water Manage. 80, 57-73.

Oweis, T., Pala, M., Ryan, J., 1998. Stabilizing rainfed wheat yields with supplemental irrigation and nitrogen in a Mediterranean climate. Agron. J. 90, 672681.

Raes, D., Steduto, P., Hsiao, T.C., Fereres, E., 2006. Structure, algorithms and functionalities of the FAO crop-water productivity model AquaCrop. In: Proceedings of the 1st International Symposium on Land and Water Management for Sustainable Irrigated Agriculture, Adana, Turkey. CD-rom.

Reekie, E.G., 1997. Chapter 8: trade offs between reproduction and growth influence time of reproduction. In: Bazzaz, F.A., Grace, J. (Eds.), Plant Resource Allocation. New York, pp. 191-202.

Ritchie, J.T., 1972. Model for predicting evaporation from a row crop with incomplete cover. Water Resour. Res. 8, 1204-1213.

Robertson, M.J., Carberry, P.S., Chauhan, Y.S., Ranganathan, R., O'Leary, G.J., 2001. Predicting growth and development of pigeonpea: a simulation model. Field Crops Res. 71, 195-210.

Soltani, A., Hammer, G.L., Torabi, B., Robertson, M.J., Zeinali, E., 2006a. Modeling chickpea growth and development: phenological development. Field Crops Res. 99, 1-13.

Soltani, A., Robertson, M.J., Mohommad-Nejad, Y., Rahemi-Karizaki, A., 2006b. Modeling chickpea growth and development: leaf production and senescence. Field Crops Res. 99, 14-23.

Steduto, P., Fereres, E., Hsiao, T.C., Raes, D., 2006. Yield response to water": the FAO revision framework and the crop-water productivity model AquaCrop. In: Proceedings of the 1st International Symposium on Land and Water Management for Sustainable Irrigated Agriculture, Adana, Turkey. CD-rom.

Steduto, P., Hsiao, T.C., Fereres, E., 2007. On the conservative behavior of biomass water productivity. Irrigation Sci. 25, 189-207.

Stöckle, C.O., Donatelli, M., Nelson, R., 2003. CropSyst, a cropping systems simulation model. Eur. J. Agron. 18, 289-307.

Tsuda, M., 1986. Effects of water deficits on panicle exsertion in rice (Oryza sativa L.) and Sorghum (Sorghum bicolor (L.) Moench). Jpn. J. Crop Sci. 55, 196-200 (Japanese; abstract and figure captions in English).

Vacher, J.J., 1998. Responses of two main Andean crops, quinoa (Chenopodium quinoa Willd.) and papa amarga (Solanum juzepczukii Buk.) to drought on the Bolivian Altiplano: significance of local adaptation. Agric. Ecosyst. Environ. 68, 99-108.

van Ittersum, M.K., Leffelaar, P.A., van Keulen, H., Kropff, M.J., Bastiaans, L., Goudriaan, J., 2003. On approaches and applications of the Wageningen crop models. Eur. J. Agron. 18, 201-234.

Vuille, M., 1999. Atmospheric circulation over the Bolivian Altiplano during dry and wet periods and extreme phases of the Southern Oscillation. Int. J. Climatol. 19, 1579-1600.

Wery, J., 2005. Differential effects of soil water deficit on the basic plant functions and their significance to analyse crop responses to water deficit in indeterminate plants. Aust. J. Agric. Res. 56, 1201-1209.

Winkel, T., Méthy, M., Thénot, F., 2002. Radiation use efficiency, chlorophyll fluorescence, and reflectance indices associated with ontogenic changes in water-limited Chenopodium quinoa leaves. Photosynthetica 40, 227-232.

Yang, S., Logan, J., Coffey, D.L., 1995. Mathematical formulae for calculating the base temperature for growing degree days. Agric. Water Manage. 74, 61-74.

Yang, H.S., Dobermann, A., Lindquist, J.L., Walters, D.T., Arkebauer, T.J., Cassman, K.G., 2004. Hybrid-maize-a maize simulation model that combines two crop modeling approaches. Field Crops Res. 87, 131-154. 